\title{
Food protein induced allergic proctocolitis: The effect of maternal Mediterranean diet during pregnancy and breastfeeding
}

\author{
Emilia Vassilopoulou ${ }^{1}$, GAVRIELA FEKETEA ${ }^{2}$, George Konstantinou ${ }^{3}$, Zekakos Xipolias \\ D. ${ }^{1}$, Gerasimina Vallianatou ${ }^{4}$, Petrodimopoulou M. ${ }^{1}$, Vasiliki Vourga ${ }^{1}$, ${ }^{*}$ Tassios $^{1}$, and \\ Nikos Papadopoulos ${ }^{4}$ \\ ${ }^{1}$ Department of Nutritional Sciences and Dietetics International Hellenic University \\ Thessaloniki Greece \\ ${ }^{2}$ Universitatea de Medicina si Farmacie Iuliu Hatieganu \\ ${ }^{3} 424$ Geniko Stratiotiko Nosokomeio Ekpaideuseos \\ ${ }^{4}$ Allergy Department 2nd Pediatric Clinic National and Kapodistrian University of Athens \\ Greece
}

October 17, 2021

\begin{abstract}
Background: The aim of the current investigation was to explore predisposing factors for food protein induced allergic proctocolitis (FPIAP) in Greek infants relevant in the maternal diet, during pregnancy and breastfeeding, as relevant knowledge is limited. Methods: A multicenter retrospective case-control study was conducted in 6 regions in Greece, with 96 mothers of infants with and 141 mothers of infants without a history of FPIAP. Maternal dietary habits during pregnancy and breastfeeding were evaluated with validated questionnaires: a) The Mediterranean Diet (MedDiet) Score, and b) The Mediterranean Oriented Culture Specific Semi-Quantitative Food Frequency Questionnaire. Statistical tests, modeling and exploration of the FPIAP risk in relation to the maternal diet using elastic net regression models were performed with $\mathrm{R}$ software and Studio. Results: FPIAP was associated with cow's milk (83.6\%), egg (7.3\%), and wheat, beef (6.4\%) in the maternal diet. Adherence to MedDiet was similar among the mothers, but mothers of FPIAP infants consumed more vegetables $(\mathrm{p}=0.018)$ and olive oil $(\mathrm{p}=0.003)$. Elastic net prediction models showed that, in this Mediterranean population, increased consumption during pregnancy and lactation of common allergens, whole grain products, homemade food, fish and shellfish, fruit offered protection; conversely, high intake of vegetables, sugar and total fat, and non-stick/grilled cooking, increased the risk of FPIAP, as did high intake of salt and white flour during lactation. Conclusions: Components of a maternal Mediterranean diet can protect against FPIAP when traditional cooking methods are adopted and fish, fruit and whole wheat products are consumed frequently.
\end{abstract}

\section{Hosted file}

AP PAI 11 10.docx available at https://authorea.com/users/321922/articles/541936-foodprotein-induced-allergic-proctocolitis-the-effect-of-maternal-mediterranean-diet-duringpregnancy-and-breastfeeding

\section{Hosted file}

Figure 1.pdf available at https://authorea.com/users/321922/articles/541936-food-proteininduced-allergic-proctocolitis-the-effect-of-maternal-mediterranean-diet-duringpregnancy-and-breastfeeding 


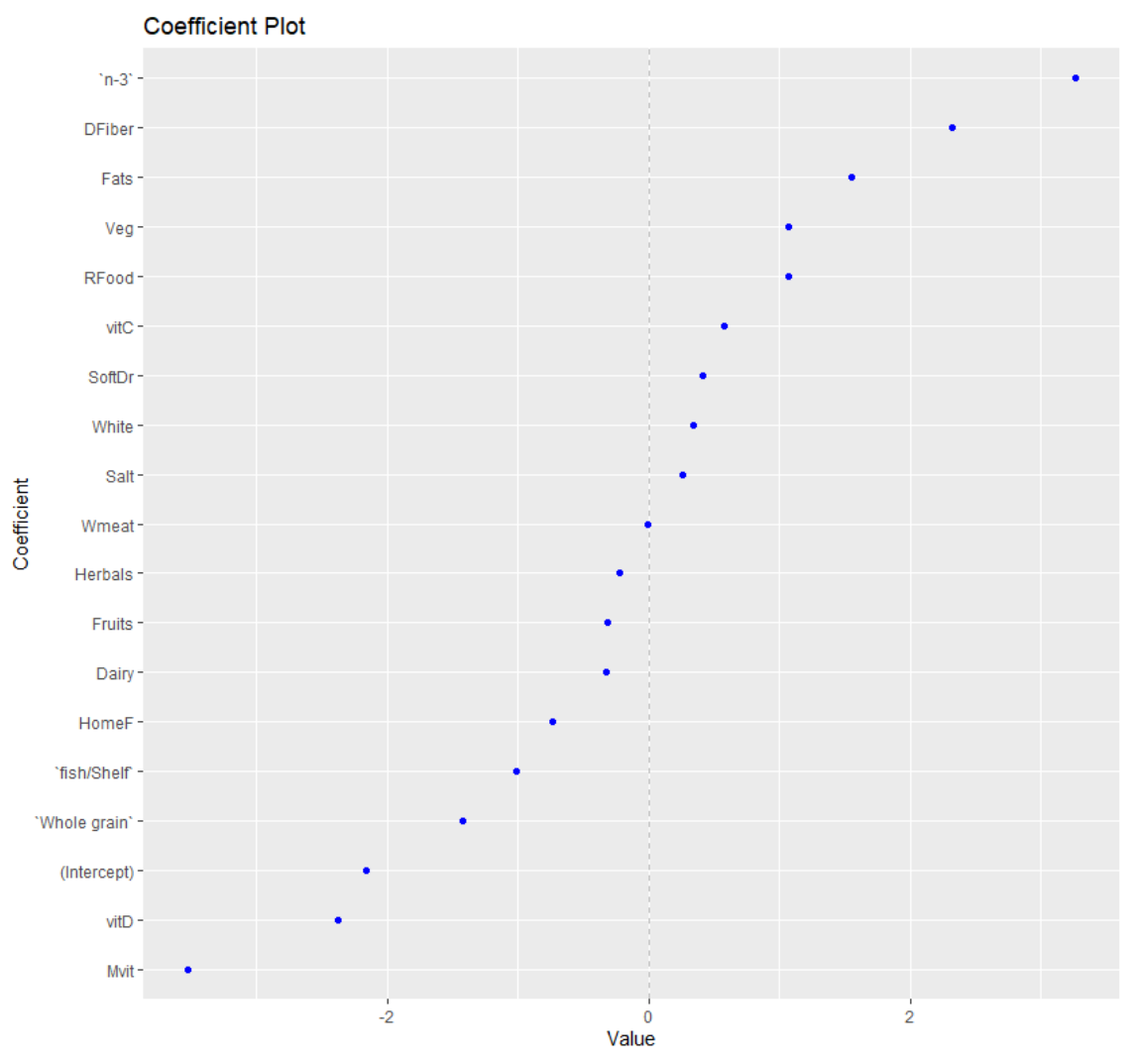

Figure 2 


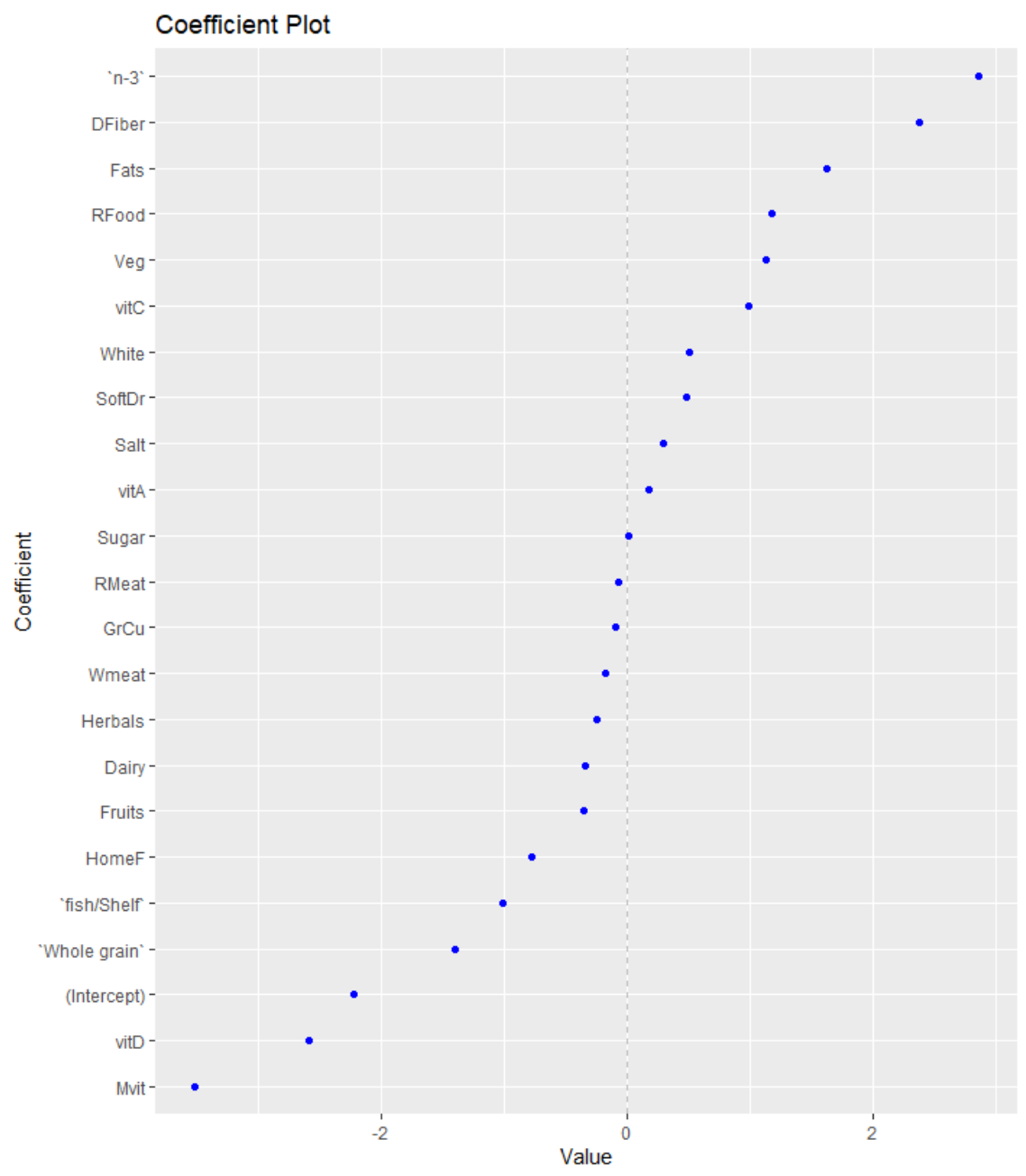

Figure 3 